\title{
Correspondence
}

\section{Transluminal angioplasty of a stenosis of an internal mammary artery graft}

Sir,

In a recent paper (1986;56:473-5) Crean et al reported successful dilatation of the anastomotic stricture of an internal mammary artery graft. They stated that "early and late stenoses develop with a similar aetiology to those in vein grafts". This is not the conclusion of the study they quote. ${ }^{1}$ On page 255 of the cited article it says "Failure of mammary grafts, early or late, was so infrequent that determinants of stenosis or occlusion could not be identified".

We would also like to point out that several recent reports suggest that an early anastomotic stricture is not due to atherosclerosis but is a surgical complication of suture technique. ${ }^{2-4}$

Ram N Singh,

Rais A Beg,

St Vincent Charity Hospital,

Cleveland, Ohio,

USA.
Julio A Sosa,

Albany Medical College,

Albany, New York,

USA.

\section{References}

1 Lytle BW, Loop FD, Cosgrove DM, Ratliff NB, Easley $\mathrm{K}$, Taylor BC. Long term serial studies of internal mammary artery and saphenous vein coronary bypass grafts. J Thorac Cardiovasc Surg 1985; 89:248-58.

2 Kereiakes DJ, George B, Stertzer SH, Myler RK. Percutaneous transluminal angioplasty of left internal mammary grafts. Am J Cardiol 1985;55:1215-6.

3 Zaidi AR, Hollman JL. Percutaneous angioplasty of internal mammary artery graft stenosis: case report and discussion. Cathet Cardiovasc Diagn 1985;11: 603-8.

4 Steffenino G, Meier B, Finci L, von Segesser L, Velebit V. Percutaneous transluminal angioplasty of right and left internal mammary artery grafts. Chest 1986;6:849-51.

\section{Long term improvement in global left ventricular function after early thrombolytic treatment in acute myocardial infarction}

Sir,

We were interested to read the report of long term improvement in global left ventricular function after early thrombolytic treatment in acute myocardial infarction by Res et al (1986;56:414-21). They noted that the improvement in left ventricular ejection fraction $(9 \%)$ after thrombolysis was greater in patients who had sustained an anterior infarction than in those with inferior infarctions. They claimed then this was due to photon attenuation. Because this difference between anterior and inferior infarction has been reported by other groups including ourselves ${ }^{1}$ it is worth examining the question of photon attenuation more closely.

Res et al used the theoretical calculations of Yeh and $\mathrm{Yeh}^{2}$ as a basis for their statement; however Yeh and Yeh examined why the ejection fraction measured by radioisotope methods gave a lower value 